\title{
THE RATES OF RECOVERY OF SEWER RAT POPULATIONS AFTER POISONING
}

\author{
By E. W. BENTLEY, A. H. BATHARD AND J. D. RILEY \\ Infestation Control Division, Ministry of Agriculture, Fisheries \\ and Food, Tolworth, Surbiton, Surrey
}

(With 1 Figure in the Text)

\section{INTRODUCTION}

Two devices have been suggested for the more economical control of rats in sewers. One is to shorten the period between successive poisoning operations and, even though some loss of efficiency may occur at each treatment, to off-set the increased cost by substituting direct poisoning for the chronic and prebaiting/acute poisoning techniques that are standard practice at present. The other is to try to eliminate the rat population, or cut it down to a very low level, by two or three closely spaced treatments - in the expectation that it will recover so slowly that it will need no more attention for a long time afterwards.

It is obvious that any attempt to evaluate empirically by field trials the merits and demerits of these alternatives would be facilitated by a knowledge of the rate of recovery of Rattus norvegicus populations in sewers after reduction by poisoning. A beginning on this problem has been made already by Barnett \& Bathard (1953), who studied the changes in two sewer rat populations subject to 6-monthly control measures. The observations described below relate to a further eight rat populations and, in particular, to three of them that were allowed to develop undisturbed for nearly 2 years after knock-down.

\section{METHODS AND RESULTS}

As in previous studies (Bentley, Bathard \& Hammond, 1955; Bentley, Bathard \& Riley, 1958) the procedure in each sewer system was first to carry out a 'census' of the population by recording for several days the $24 \mathrm{hr}$. consumption of wheat from a surplus maintained at the bottom of about fifty widely scattered manholes-usually located at street junctions. Next followed a poison treatment at all manholes in the system and, soon afterwards, a further census. From the figures for the last 3 days of the first and second censuses an estimate was made of the percentage reduction of the population. In systems F-H (see Fig. 1) the procedure thereafter was simply to carry out further censuses at approximately 3- to 6monthly intervals. In systems A-E only one more census was possible: this occurred in each case 6 months after poisoning.

\section{System $A$}

This was a complete network of nearly 300 manholes in a small country town in Essex. Observations were slightly complicated by the presence under the town 
of a culverted stream into which discharged a number of storm-water and foul sewers.

Previous poisoning treatments in A had been carried out regularly and conscientiously and it was only lightly rat infested. Nevertheless, it seemed to have been the source of a number of recent infestations in surface properties. Of the 295 baitable manholes, fifty-two were chosen as census points and rats were active at thirteen of these. Consumption of wheat reached a peak on the third day and the average for days 6-8 was $478 \mathrm{~g}$. Poisoning took place in November and a few days later the post-poisoning census began. This was discontinued after 6 days since there were no signs of rats. Nor were rats present in the culverted stream which was poison-baited along its whole length, simultaneously with the sewers.

Six months later, rat activity was apparent at only one of the fifty-two 'census' manholes, an average of $50 \mathrm{~g}$. of wheat disappearing during days 5-7. No rats appeared to be living along the stream. Strict interpretation of the census figures means that the population was restored to $10-11 \%$ of its former size from zero in 26 weeks; but a more realistic picture of the position in A after 6 months is obtained by recalling that $50 \mathrm{~g}$. of wheat are within the daily eating capacity of two fully grown rats.

\section{System $B$}

System B, of 353 manholes, was situated in a small, hilly, urban district between Leeds and Huddersfield and at several points along it two or more lines ran into the same manhole chamber at different levels, making it too wet for baiting to be possible. In spite of regular poisonings, a medium-sized population of rats was present. The census was confined to forty-nine manholes and the mean take for days 7-9 was 1633 g. (a minimum of perhaps sixty to seventy rats). Poisoning took place in December and at the post-poisoning census the corresponding figure was 225 g.-indicating a kill of $86 \%$.

At this stage, unfortunately, because the procedure in System B (and in C, D and $\mathrm{E}$ also) was not primarily directed towards the study of recovery rates, a further poisoning was done at eight of the census manholes that were still infested. This limits the value of the second census carried out 6 months later when a mean daily consumption of $210 \mathrm{~g}$. was recorded. However, a valid conclusion is that the part of the population sampled by baiting at the forty-nine census manholes increased from some point between zero and $14 \%$ of its former level to no more than $13-14 \%$ again, in a period of 23 weeks between December and May.

\section{System $C$}

System C, of 203 manholes, was part of a larger network of sewers serving a town in the West of England. It was fairly self-contained but was connected with the rest of the system at four or five points. Many parts of it were subject to flooding owing to insufficient run-off capacity. The district through which $\mathrm{C}$ ran consisted partly of old residential property and partly of a council-house estate. In spite of regular poisonings over several years the rat population was persistently higher than is normal for this type of sewer. 
The average daily take of wheat for the last 3 days of an 8-day census at fifty manholes was $2848 \mathrm{~g}$. (100-200 rats?). The poison treatment, which took place in July, was terminated by the severest storm that the town had experienced for over 20 years and at the following census, which perforce had to be done as soon as the floods had subsided, a kill of $95 \%$ (143 g.) was indicated. In the following January, 26 weeks later, the final census figure was $2432 \mathrm{~g}$.- equivalent to a recovery to $86 \%$ of its former level at a constant rate of $11.5 \%$ per week.

\section{System $D$}

System D, containing 140 manholes, formed part of a much larger system serving a residential town, also in the West of England. Sections of it were of remarkable antiquity and incompletely mapped. Several of the manholes in the middle of the town were very deep and a few were unbaitable. In spite of its central position System D was separated on three sides from the rest of the sewers of the town because it lay in a $\mathrm{U}$-shaped bend of a river. As in $\mathrm{C}$ there was a history of twiceyearly poison-baiting without obvious signs that the rat population was being permanently reduced. Some poisoning had been carried out not many weeks previous to the experiment and the level of the population was therefore probably below its potential maximum.

At the first census, embracing fifty manholes, the average take of bait over days 7-9 was $1758 \mathrm{~g}$. Poisoning was carried out in late June and the average take for the last 3 days of the second census was only $102 \mathrm{~g}$.- - suggesting that a kill of about $94 \%$ had been achieved. As in System B, a second poisoning was carried out at the manholes still showing takes at the second census. However, there were only six of these, and as it turned out, treating them twice is hardly likely to have affected the outcome. For at the third census, carried out 27 weeks later, the population seemed to be even a little higher than at the beginning of operations, the mean daily take amounting now to $2088 \mathrm{~g}$. This corresponds to a minimum weekly rate of increase of $11 \cdot 8 \%$.

\section{System $E$}

System E, containing 135 manholes, was situated in a mixed industrial and poorclass residential district of a large midland town. The sewers were old and remarkable for the very great distances between manholes. In some cases these were over $\frac{1}{2}$ mile apart and road subsidences due to sewer-rat excavations had occurred in the area.

The first census, at forty-nine manholes, produced a mean daily take over the last $72 \mathrm{hr}$. of $3333 \mathrm{~g}$. of wheat. After poisoning in June, the take fell to $240 \mathrm{~g}$.corresponding to an apparent reduction of the population to $7 \cdot 2 \%$. As in systems $\mathrm{B}$ and $\mathrm{D}$, a second poisoning was carried out at certain manholes just after the post-poisoning census. But again, as in $\mathrm{D}$, this does not detract much from the information obtained at the next census, 29 weeks later. For by this time the population had already recovered - as indicated by the final mean daily take of $3690 \mathrm{~g}$.- - equivalent to a minimum weekly rate of increase of $9 \cdot 8 \%$. 


\section{Systems $F, G$ and $H$}

Systems F-H were sectors of a larger sewer network which drained a mixed residential and industrial borough on the west side of London. The district was very much intersected by railways and this and other factors meant that the three sewer subsystems were so distinct that the likelihood of rats migrating from one to the others was minimal. There was, however, some possibility of migration into $\mathrm{F}$ from outside. Owing to labour difficulties the maintenance of the sewers left something to be desired and silting-up (which causes stranding of refuse and therefore provides more food for rats) increased somewhat during the observations. A notable feature of the whole network was the consistently short distance between successive manholes.

Sewer $F$ contained 265 baitable manholes. In the north it drained a good-class residential area while in the south, slum clearance was taking place--a process that may have temporarily decreased the amount of food available to rats. There were no large factories but the presence of a number of laundries and other small concerns meant that rapid and irregular changes occurred in the level of the effluent.

Sewer $G$ included 251 baitable manholes and was situated in a mixed area of well-maintained terrace houses, some shops, blocks of flats and small factories from which, probably, only moderate amounts of food were reaching the sewers. Here again the effluent varied very much in volume.

Sewer $H$, of 265 baitable manholes, drained a residential area of well-maintained blocks of flats and of large houses, many of which were converted into flats.

The detailed course of events in Systems $\mathrm{F}-\mathrm{H}$ is summarized in Table 1 but its main outline may perhaps be more easily appreciated from Fig. 1 . In $F$ the poison treatment was not very successful and only reduced the population to an apparent $38 \%$. Twenty-six weeks after the post-poisoning census it was back at its former level. It may have reached $100 \%$ in less than 26 weeks but this is not very probable since the population was even higher $(146 \%)$ by the 45 th week; thereafter it appeared to recede and was back near its initial size by the end of 2 years.

It may be assumed that at the beginning of the experiment the population in $F$ was at the maximum that the sewers could sustain at that time: for the previous poison treatment was probably even less efficient than the experimental one and in any case took place 21 months earlier. This does not mean that the peak at the 45th week was not real. For it is quite probable that sewer populations continually fluctuate to some extent through the operation of various factors such as the incidence of heavy storms and the slum-clearance work already noted as occurring in $\mathbf{F}$.

In System G, where there may have been more rats than in $\mathrm{F}$, the poison operation appeared to have reduced the population to about $28 \%$. After 26 weeks it had recovered to about $61 \%$ and finally became steady at, or slightly above, its initial level in 10-11 months.

In System $\mathbf{H}$, which probably carried the lightest population, the kill was greatest $(89 \%)$ and it was nearly 2 years after poisoning before recovery was complete. 
The various mean weekly rates of increase of the rat populations in Systems F, $G$ and $H$ between censuses are set out in Table 2 . The highest rate $(6 \%)$ occurred during the first 26 weeks of the recovery period in $\mathrm{H}$-where the population had suffered the greatest reduction (to $11 \%$ ). Thereafter, in $\mathrm{H}$, recovery was slower than in Systems $F$ and $G$, in both of which the overall rate was about $3 \%$ per week.

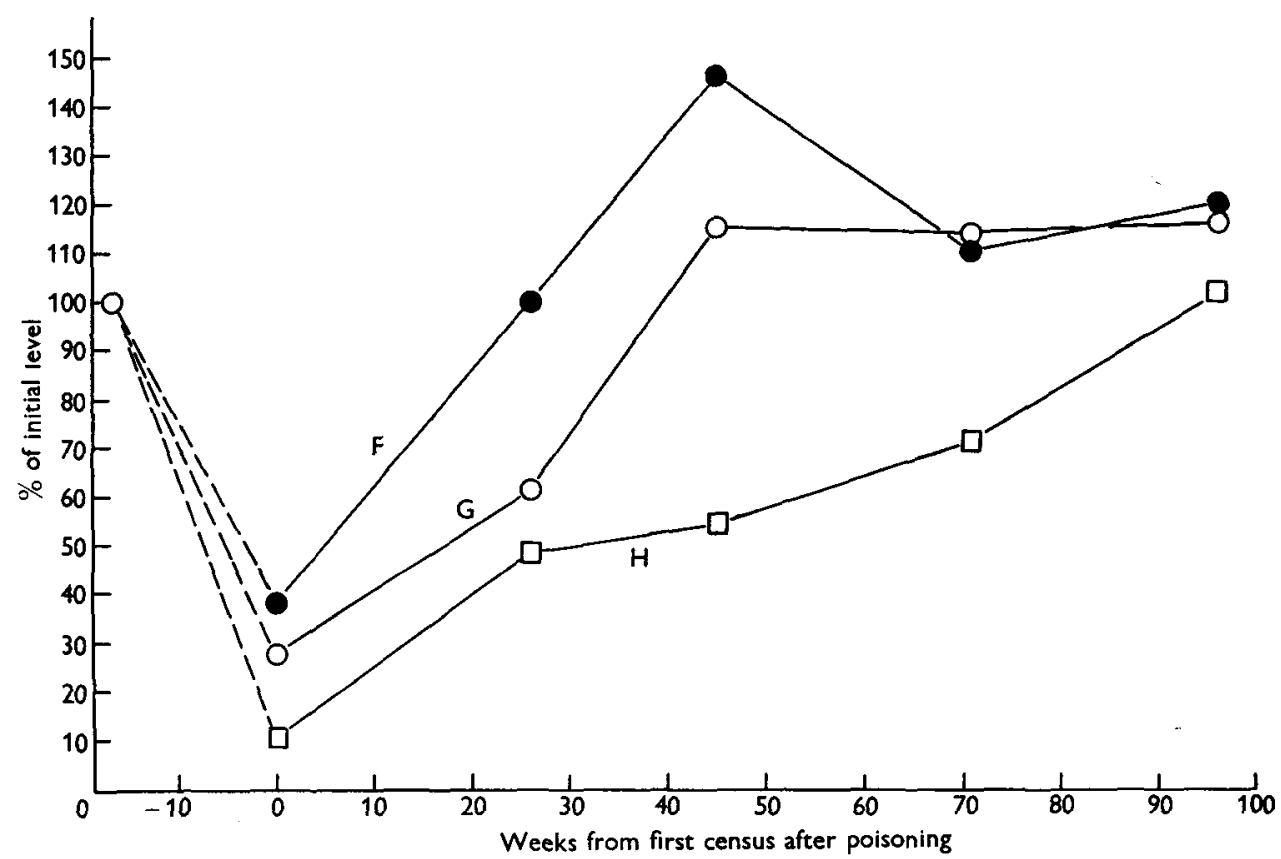

Fig. 1. Population changes in Systems F, G and $H$ during 2 years, expressed as percentages of the levels before poisoning.

Table 1. Mean takes of bait at successive census operations and estimated percentage recovery of the populations in Systems $F-H$

\begin{tabular}{|c|c|c|c|c|c|c|c|c|c|c|c|c|}
\hline \multirow[b]{2}{*}{ System } & \multicolumn{2}{|c|}{$\begin{array}{c}\text { Pre- } \\
\text { poisoning } \\
\text { census }\end{array}$} & \multicolumn{2}{|c|}{$\begin{array}{l}\text { Post- } \\
\text { poisoning } \\
\text { census }\end{array}$} & \multicolumn{2}{|c|}{$\begin{array}{c}26 \text { weeks } \\
\text { later* }\end{array}$} & \multicolumn{2}{|c|}{$\begin{array}{l}45 \text { weeks } \\
\text { later* }\end{array}$} & \multicolumn{2}{|c|}{$\begin{array}{c}71 \text { weeks } \\
\text { later* }\end{array}$} & \multicolumn{2}{|c|}{$\begin{array}{c}96 \text { weeks } \\
\text { later* }\end{array}$} \\
\hline & g. & $\%$ & g. & $\%$ & g. & $\%$ & g. & $\%$ & g. & $\%$ & g. & $\%$ \\
\hline $\mathbf{F}$ & 2633 & 100 & 1011 & 38 & 2633 & 100 & 3856 & 146 & 2898 & 110 & 3145 & 119 \\
\hline G & 3088 & 100 & 855 & 28 & 1888 & 61 & 3565 & 115 & 3507 & 114 & 3578 & 116 \\
\hline $\mathbf{H}$ & 2033 & 100 & 215 & 11 & 988 & 49 & 1105 & 54 & 1439 & 71 & 2069 & 102 \\
\hline
\end{tabular}

\section{DISCUSSION}

The apparent rate of recovery of a sewer rat population after poisoning obviously depends upon the sampling efficiency of the census method employed to measure it, the amount of migration into or out of the area and the breeding capacity of the survivors.

In so far as the efficiency of the bait-census method is measured by the degree 
to which it gives repeatable results in a given set of circumstances, using it in sewers for several years has convinced us of its reliability. However, we have shown elsewhere (Bentley et al. 1955) that in a certain type of system-particularly where the drains are structurally poor and manholes are far apart-it may fail to take into account animals living between manholes and only rarely visiting them. This disadvantage may be expected to operate both when the population is low and when it is high: but, in the latter case, probably not to the same extent. The result therefore may be to underestimate the size of the population when it is low.

We believe that in two of the eight systems studied our census probably gave a false picture-in each case overestimating the kill at poisoning and thus exaggerating the rate of recovery of the population. In $\mathrm{C}$ it is surmised that the spectacular flooding that occurred at the end of the poisoning operation, probably drove the surviving rats out of their normal territory, up to drier levels, and that the post-census was carried out before the population had settled down again. In $\mathbf{E}$, the enormous distance between some of the manholes undoubtedly enabled rats to survive the poisoning undetected by the second census. It is possible that in $D$, too, the existence of unmapped drains under the town led to a similar resultthough this is much less certain than in the case of $\mathrm{E}$.

Table 2. Mean weekly percentage increase of the rat populations in Systems $F, G$ and $H$

$\begin{array}{cccccccc} & \text { 26 weeks } & 19 \text { weeks } & 26 \text { weeks } & \begin{array}{c}25 \text { weeks } \\ \text { Apr./May- }\end{array} & \begin{array}{c}\text { Overall } \\ \text { Oct./Nov.- } \\ \text { Mate }\end{array} & \begin{array}{c}\text { Overall } \\ \text { rate }\end{array} & \begin{array}{c}\text { Overall } \\ \text { rate }\end{array} \\ \text { System } & \text { Oct./Nov. } & \text { Mar./Apr. } & \text { Sept. } & \text { Mar. } & 45 \text { weeks } & 71 \text { weeks } & 96 \text { weeks } \\ \text { F } & 3 \cdot 8 & 2 \cdot 1 & - & - & 3 \cdot 0 & - & - \\ \text { G } & 3 \cdot 0 & 3 \cdot 4 & - & - & 3 \cdot 2 & - & - \\ \text { H } & 6 \cdot 0 & 0.6 & 1 \cdot 0 & 1 \cdot 5 & 3 \cdot 7 & 2 \cdot 7 & 2 \cdot 4\end{array}$

Migration may take place from the surface or from adjacent connecting sewers. This is usually difficult to detect and is much more difficult to evaluate. Migration from the surface is unlikely to have occurred to any appreciable extent during the observations in Systems B, C, F, G or H. It may easily have occurred, however, in $\mathrm{E}$ and very probably occurred in $\mathrm{D}$. A search of the above-ground environs of $D$ after the third census established the fact that several storm-water sewers, if not one or two foul sewers, discharged into the river that partly surrounded it: and the river bank was heavily infested with rats.

Leslie (1945) gives the figure of $0 \cdot 104$ per head per week for the inherent rate of increase of laboratory populations of $R$. norvegicus. In a subsequent publication (Leslie, Venables \& Venables, 1952) the constant, relative rate of increase of a population of rats living in the highly favourable conditions found in corn-ricks was shown to be about 0.08 to $0 \cdot 10$ per head per week. In our opinion, it is most unlikely that an overall rate as high as this could be maintained for long in the great majority of sewer systems, in spite of indications that the higher winter temperature may encourage continuous breeding throughout the year.

Table 2 suggests that a more likely inherent rate of increase after reduction by poisoning would be about $3 \%(0.03$ per head per week) with perhaps a higher initial 
rate in some circumstances - depending, perhaps, on the age and sex composition of the surviving population. For in Systems $\mathbf{F}-\mathbf{H}$, owing to the short distances between manholes, conditions for accurate census baiting were good and migration was probably non-existent. In each system, therefore, the increase in numbers observed may be attributed solely to breeding. This does not apply to Systems C, $D$ and $E$ where, as explained above, the respective rates of increase of $11.5,11 \cdot 8$ and $9 \cdot 8 \%$ that were obtained may be partly attributed to difficulties of census or to migration from the surface and from adjacent sewers.

An increase of $3 \%$ per week is only equivalent to just over a twofold increase in 6 months and less than a fivefold increase in a year. This means that (where reinvasion of the sewers from outside does not occur) cutting down the population to, say, $10 \%$ or less not only gives an appreciable measure of relief but may make it an economical proposition to spend more money in immediately reducing the population still further. This will be particularly so if the points where the remaining rats are located are known and can be given special attention-preferably a poison treatment with a chronic rodenticide.

A, B, F, G and $\mathbf{H}$ were all examples of systems in which such a policy would normally be profitable. A and B, for instance, were quite unconnected with other sewers and rats were infrequent above ground. As already stated, A remained almost free from rats for 6 months after what appeared to be a completely successful poison treatment, while the rat population of $B$ probably recovered only slightly during the same period.

Accepting the thesis that the breeding rate of rats in sewers seldom leads to much more than a $3 \%$ increase per week also means that in sewer systems in which immigration is important-unless this can first be prevented or minimized-there is little point in putting extra effort into trying to improve the efficiency of poison treatments that already give a fairly reasonable kill. The measures necessary for cutting down migration of rats into sewers will vary, of course, from place to place. Commonly, they include reduction of surface infestations, inspection and repair of surface drains, arranging overlapping of adjacent sections of the system if they cannot be poisoned simultaneously, and timing poison operations to coincide with those in connecting sewers belonging to a neighbouring authority: also instituting more frequent control operations at suspected immigration points and taking precautions such as temporarily sealing off, between working shifts, sewers under construction or repair.

Of the systems studied by us, D was an obvious case where immigration played a big part in the recovery of the rat population and where it could largely have been prevented-by controlling the rats on the bank of the surrounding river and, perhaps, by fitting more efficient flaps or other proofing devices to the drains discharging into the latter. Immigration would have been possible also into $A$, at the point where the stream disappeared into the culvert, had not measures been taken during our observations to control the rats living in the immediate vicinity. 


\section{SUMMARY}

1. The recovery, after poisoning, of the rat population of eight sewer systems was measured by the bait-census method.

2. In three of the systems the mean rate of increase was of the order of $3 \%$ per week. This is attributed solely to breeding and is regarded as typical for rats in sewers.

3. Higher rates of increase (up to $11.8 \%$ ) were also recorded but are believed to have been partly due to immigration or to have been only apparent (as a result of census difficulties).

4. The consequences for control of a rate of increase as low as $3 \%$ per week are discussed.

Our thanks are due to eight Local Authorities, their Chief Public Health Officers and members of their staffs, without whose help the work would have been impossible, and to a number of colleagues, especially Mr J. H. Greaves, who helped with much of the census work.

\section{REFERENCES}

Barnett, S. A. \& Bathard, A. H. (1953). Population dynamics of sewer rats. J. Hyg., $C a m b ., 51,483$.

Bentley, E. W., Bathard, A. H. \& Hammond, L. E. (1955). Some observations on a rat population in a sewer. Ann. appl. Biol. 43, 485.

Bentley, E. W., Bateard, A. H. \& RiLey, J. D. (1958). The control of rats living between access points in sewers. J. Hyg., Camb., 56, 19.

Lest E, P. H. (1945). On the use of matrices in certain population mathematics. Biometrika, $33,183$.

Leslit, P. H., Venables, U. M. \& Venables, L. S. V. (1952). The fertility and population structure of the brown rat (Rattus norvegicus) in corn-ricks and some other habitats. Proc. zool. Soc. Lond. 122, 187.

(MS. received for publication 6. IV. 59) 